\title{
Pedagogical intervention to improve didactics through science and innovation
}

Antonio Jesús Pérez Sierra, Julio Montes Brown, Denisse Danya Rodríguez Maldonado, Héctor Manuel Sarabia Sainz, \& Juan Francisco Viera González

\author{
Department of Sports Sciences, University of Sonora, Mexico \\ Department of Medicine University of Sonora, Mexico \\ Department of Psychology, University of Sonora, Mexico \\ Department of Sports Sciences, University of Sonora, Mexico \\ Department of Engineering, University of Sonora, Mexico
}

${ }^{1}$ Corresponding author: Antonio Jesús Pérez Sierra, antonio.perez@unison.mx

University of Sonora, Rosales \& Blvd. Luis Encinas, P. O. Box 1658, C.P. 83000, Hermosillo, Sonora, Mexico

\section{Introduction}

In these last decades of this 21 st century the world has changed rapidly, where students and teachers need to adapt to these social transformations, to provide us with tools that allow us to prepare for the relentless academic, labor and research transitions to solve problems, based on science and innovation as an alternative way to scientific and technological advances, for the development of progress in education systems, and even more so for university students.

From the above analysis, we can ask the following question What is the role of pedagogical intervention in improving didactics through science and innovation? To answer this question, it is important to plan, organize and structure complex systems for modifying the teachinglearning process; as well as methodological procedures, through the structural categories of didactics such as: objectives, content, methods, forms, didactic strategies means of teaching, evaluation.

Over time these procedures have changed, in order to redesign the teaching-learning process, transformations must be carried out in an orderly and methodical manner, to describe the actions of each discipline in a particular way, within them, involves perfecting theories, practices to discover and sustain pedagogical intervention to improve didactics through science and innovation.

\footnotetext{
${ }^{1}$ Corresponding author: Antonio Jesús Pérez Sierra, Universidad de Sonora antonio.perez@unison.mx
} 
In this regard, Bunge (2017), proposes that...

The theory of theory consists of the method, by the theory of knowledge (epistemology) lies in a clear rebuttal of theories through the observation of nature and the experimentation that constitute the essence and success, of the scientific method. (p.3).

According to Pierre \& Pollán (1979), "many teachers do not teach their classes since educational research, where they accompany educational disciplines or at least the disciplines traditionally recognized as (pedagogical, didactic and sociological) of education". (p. 2).

Science and innovation to improve didactics is a path of pedagogical intervention of relevance to constitute scientific and critical reflection with the aim of efficiently solving the development and improvement of the mission of education, according to Ortiz (2015).

With this, the processes of production and application of knowledge are currently used to explain the role of science and innovation, seeking a common good for educational development. (Fernández et al., 2011).

According to what Pérez y Zagalaz (2001) raised, as is known...

Logical analysis of the behavior of human civilization in the modern was inevitably leads us to science, technique and research as a bulwark of advancement to provide on a greater or smaller scale all spheres of social life of the higher and higher middle educations. (p.1).

In the field of education where there are multiple opportunities to develop science based on method and innovation in the teaching field, teachers must take the opportunities to teach more dynamic classes that break paradigms and outlines, starting from pedagogical intervention to improve didactics through science andinnovation, according to the experience of practice of each teacher.

It is important that the didactic and methodological process for pedagogical intervention to improve didactics through science and innovation, start from the integral training of future professionals, taking into account their needs, and the specific social context that students take. In the scientific and innovative context to improve the paths of the teaching-learning process, we must define new forms of teaching; has been modified by certain social needs; according to the contents they must respond to the social context, being increasingly complex day to cover the training of more integral subjects, complying with the pillars of education (being, know-how, knowing sharing and knowing coexists).

Teachers must do training to deliver more meaningful results on science and innovation as a hope to develop new theories about the elements of the structures that make up the components of the 
teaching-learning process; in other words, a paradigm shift on pedagogical intervention such as objectives, content, methods, forms, didactic strategies teaching means, evaluation.

\section{Pedagogical intervention to improve didactics}

According to the Secretariat of Public Education (SEP, 2009), it considers that...

Educational research has sought to pin down solid knowledge; because its realization involves the incorporation and mobilization of specific knowledge to develop in students competencies, which are based on knowledge, skills, values of the consequences of attitudes. (p.4).

Teachers as decisive agents in the change of didactics from the real pedagogical; in addition to proposing the elements of knowledge of the subjects that have the faculties of science as a determining element that influences the progress of teaching in an effective way for educational quality (Mellado, 1996).

Science and innovation are achievements that have contributed to improving the educational practices of teachers in the development of teaching-learning that students are trained and developed, based on the methods of science; because of the complex and dynamic changes it has produced.

Education in our country has made major changes to curriculums and programs, where science is linked to teaching for the development of didactic and pedagogical work in educational institutions, which aim to convey the full cluster of knowledge based on science and innovation to improve didactics, where we must pass on complex information to students to understand the phenomena of reality objective, and how these affect the daily lives of human beings.

Because of these social changes, teachers should rely on pedagogical and didactic science, in accordance with vocation and professionalism to teach in their educational practice, research to develop practice skills to verify and understand the significant learnings expected by students. According to Benitez (2016), "from this set of reforms and changes, the most controversial relate to the evaluation process on the performance of teaching work, especially if it is about changing and innovating in practice in the classroom". (p.43).

\section{Didactics}

According to Abreu et al. (2017), They propose that...

The main exchange has focused on the origins of the conditions of the object of study of science, its structural categories of didactics, laws, principles, its pillars, evolution, its general or disciplinary character and its relationship with Pedagogy, Didactics and methodologies. (p. 81). 
It is understood that didactic innovation refers to changes in the teaching-learning process and these may be related to changes in curriculum content; in addition, of the structural categories of didactics such as: objectives, content, methods, forms, didactic strategies means of teaching, evaluation. (Macanchí et al., 2020).

It is important that teachers participate in the construction of new teaching knowledge, providing possible solutions to the problems that teaching that arise in pedagogical interventions to improve didactics through science and innovation (Briscoe, 1991).

The following table expresses the aspects that make up the scientific nature of pedagogical intervention to improve didactics.

Tabla 1

Scientific nature of pedagogical intervention to improve didactics.

\begin{tabular}{|c|c|}
\hline Cscientific aacter & Pedagogical intervention to improve didactics \\
\hline Object & Teaching-learning process. \\
\hline Laws & $\begin{array}{l}\text { The dialectical unit between objective and method as } \\
\text { guiding categories of the teaching-learning process, } \\
\text { instructional process and education. }\end{array}$ \\
\hline Pillars & $\begin{array}{l}\text { Linking theory with practice, according to the pillars of } \\
\text { education (being, know-how, knowing how to share and } \\
\text { living knowledge). }\end{array}$ \\
\hline $\begin{array}{l}\text { Principles and its } \\
\text { relationship to the } \\
\text { University's vision }\end{array}$ & $\begin{array}{l}\text { Principles are necessary for pedagogical intervention for the } \\
\text { implementation of the teaching-learning process and the } \\
\text { application of science and innovation to improve didactics } \\
\text { and their linkage with }\end{array}$ \\
\hline & Vision of the University of Sonora. \\
\hline Rules & $\begin{array}{l}\text { From the usual to the particular, from what, known to the } \\
\text { unknown, from the simple to the complex. }\end{array}$ \\
\hline $\begin{array}{l}\text { Structural categories of } \\
\text { didactics }\end{array}$ & $\begin{array}{l}\text { Objectives, content, methods, forms, didactic strategies } \\
\text { means of teaching, evaluation. }\end{array}$ \\
\hline
\end{tabular}

As Arteaga et al. argues (2016), in conceiving that ...

The teaching of science has an indispensable duty to prepare the human being for the time it is for him to live, this is not obtained alone by imparting knowledge of 
the contextual environment; but the sea applicable to science to solve the problems of social life. (p.169).

That is, the teaching-learning process must be designed by the academic and research components with the aim of solving the problems that affect pedagogical intervention to improve didactics through science and innovation, where it aims to train and develop integral students as competent future professionals.

Understand the teaching importance as a determining component to publicize the knowledge of science, which influences scientific advances derived from research and innovations to improve didactics in pedagogical intervention. (From Longhi, et al., 2004).

Didactics is the discipline that makes up the teacher's act of transmitting teaching, in an accessible and affordable way, in order for students to learn, understand and address the most pressing problems of the teaching-learning process, according to structural categories, even from a peculiar disciplinary formation prior to the constitution of education and pedagogy. (Diaz, 1998). All educational institutions must have a responsibility to encourage and promote educational science and innovation as a welfare of the continuous improvement of didactics in pedagogical intervention.

The sciences cover various levels of student rapprochement, the structure with which their learning experiences and activities are being formed, constitutes a guide to innovation in the educational context, hope to improve the teaching process to change the teaching process its relationship with Mexican education, considering that science has managed to contribute to improving the educational practices of teachers, depending on the development of the teachinglearning process.

The teaching of science in education, where it seeks to consistently justify the set of problems that are systematically manifested so that teachers are facilitators and drivers of an excellent process of teaching-learning the educational context; thus improve learning activities, which broaden the perception of the different phenomena that occur during the teaching-learning process; so build an analysis of a representation, synthesis, reflection and interpretation closer to reality.

Can we ask ourselves the questions If teachers rely on science to better optimize teaching in classes? How do teachers leverage science and innovation to improve didactics through their pedagogical intervention?

With regard to the questions raised, we teachers have the responsibility to contribute more efficiently, effectively and effectively, to achieve the purposes of making available the foundations of theoretical, empirical and methodological knowledge, giving a primary place to 
research, this promotes the search for new alternatives so that there is greater reliability and validity of methods in the awakening and interest and interest of students, through pedagogical intervention to improveactics through science and innovation.

The innovative initiative that characterizes teachers and unfortunately retracted by taught programs that, while flexible, the creativity of those who implement in schools is limited to transmitting content to students.

Didactics has countless structured concepts, judgments and reasoning capable of generating new ideas for integral teaching, such as the crankcase of objectives and the use of methods, as primary ways to transmit content from the cognitive, affective and emotional.

\section{Science}

To speak science is to refer to the main support of human activity in order to transform the reality that can be investigated from the theoretical and empirical methods of human reasoning to give answers to hypotheses; through the different scientific methods, and to be able to make decisions to advance cultural and artistic thinking as the basis of analytical, reflective, critical, humanistic and constructivist instruction of the art of teaching.

Science seeks truth with the relationship between the epistemological, ontological, axiological and methodological, this link allows teachers to apply their knowledge to obtain better results in the field of pedagogical intervention.

Science allows us to make decisions to accept or reject scientific theories based on the results of empirical methods as an example: observation, experiment, measurement, survey, questionnaire, interview, which are conceived as important empirical methods, real science proposes models of scientific development that explain changes in paradigm theories. Based on theoretical methods such as: analysis-synthesis, inductive-deductive, modeling, systemic, theoretical-deductive and historical-logical approach.

To respect, Garcia (2008), "it is certainly expressed that the idea of a method that contains firm principles, immovable to conduct scientific activity with the results of research". (p. 194).

Science has led modern societies to live scientific advances that cover all unthinkable areas, from medicine, agriculture, nuclear energy to technological advances, this is where we need to intervene, seek and propose new knowledge for the science of analysis, synthesis, reflection and interpretation and criticism, to make the educational context more dynamic and divergent in the Universities of Sports Sciences and Physical Activity.

The science that seeks truth is the axiological, creativity and innovation aspects indispensable for pedagogical and didactic problems for the solution of the educational context, which is reflected 
as a complex process to propose varied responses to didactic improvements.

We can refer to two equivalents on"science is not only knowledge, but the expression and systematics of this" Monserrat (1987). Thus for Zimmy (1961), "scienceis the organized set of knowledge gathered with the use of systematic observation"quoted by (Albert, 2007).

\section{Innovation}

Teachers have a responsibility to continuously transform our teaching practice; based on the new changes in the educational context to improve didactics and encourage in our students a creative, flexible thinking, with perspectives of analysis, valuation and interpretation, and above all with the depth required to understand the phenomena of social needs.

As Ezpeleta (2004)proposes, "science and innovation mean that for decades studies have changed in the education sector, he notes that innovation and teaching practice are more likely to succeed when they have emerged from schools themselves." (p.404).

When we talk about innovation it is important that we want an improvement to change the common well-being environment, which refers to an innovator for innovator, or change for change.

With regard to what Sanchez raised (2005), referring to how to...

The aim is to improve the process of intentionality of the teaching-learning process with a clear purpose for all of us to improve the efficiency, effectiveness and effectiveness of the quality of the educational process, through science and innovation in the application of methods and strategies that will solve the set of problems of planning and organization at the didactic level. (p.640).

From the position of Margalef and Arenas (2006),"innovation is the creation of something unknown, the perception of what is created as something new and the assimilation of something likenew." (p.14).

Educational innovation is much more related to technologies, and teaching strategies, and does not refer to changes in the educational context to raise awareness of the importance of science and innovation in the performance of class structuring planning structures, with a didactic and methodological foundation based on information and communication.

For Tierney \& Lanford (2016), referring to...

Higher education is currently facing global forces that require innovative research, innovative pedagogies and innovative organizational structures. For these reasons, we suggest that a theoretical understanding of innovation is imperative for the continued development of higher education in the 21 st century. 
Bearing in mind, as expressed by Carbonell (2001), "bydefining innovation as a series of interventions, decisions change attitudes, ideas, cultures, content, models and pedagogical practices". (p.15).

Innovation implies something new for someone and that the novelty of the sea assimilated for the common well-being of the education system.

Citing González and González (2017a), "innovationentails changes that lead to the transformation of the object to improve educational practice". (p.9).

In other words, innovation can be defined as a determining element for educational development, socio-economic scientist at national and international level in search of better solutions for the well-being of school management and quality of teacher performance efficiently; it is then decisive to achieve the success of the teaching-learning process, which innovation plays a leading role from the cognitive, socio-affective dimensions for creation and improvement. (War et al., 2014).

We believe that science and innovation are necessary tools that guarantee the quality of teaching work, these foundations bring us a relationship between the knowledge they establish in the different levels of teachings of the education system, in essence the Sports Sciences and Physical Activity.

Themain objective of this article is to analyze pedagogical intervention to improve didactics through science and innovation of the teaching-learning process of Sports Sciences and Physical Activity.

\section{Materials and Methods}

The research we propose is qualitative, the type carried out is descriptive, based on a nonexperimental design, it is intended to deepen pedagogical intervention to improve didactics through the science and innovation of the teaching-learning process of teachers during their area of action; in addition, to know the perception of students the degree in Sports Sciences and Physical Activity.

\section{Participating subjects}

The participants for this research are the 31 students of the Bachelor's Degree in Physical Culture and Sport of the University of Sonora, corresponding to the eighth semester, composed of 16 correspond to the female gender for the (51.62\%), and 15 students remaining, which are of the male gender for (48.38\%). The eight teachers, five belong to the female gender for $(62.5 \%)$, and three to the male gender for $(37.5 \%)$. The selected population was intentionally, 
for more information check Table 2 .

Table 2

Participating subjects and gender.

\begin{tabular}{cccccc}
\hline \multirow{2}{*}{ Subject } & $\begin{array}{c}\text { Participating } \\
\text { subjects }\end{array}$ & \multicolumn{2}{c}{ Gender } & \multicolumn{2}{c}{$\%$} \\
\cline { 2 - 6 } & 31 & $\mathrm{~F}$ & $\mathrm{M}$ & $\mathrm{F}$ & $\mathrm{M}$ \\
\hline Students & 16 & 15 & 51.62 & 48.38 \\
Teachers & 8 & 5 & 3 & 62.5 & 37.5 \\
\hline
\end{tabular}

Document Review: The different revised documents were used to understand and deepen whether there are research-related aspects; in addition to determining the level of knowledge of pedagogical intervention to improve didactics through science and innovation. This allowed us to establish adaptations in the different components of the teaching-learning process the redesign of these structural categories of didactics such as (objectives, content, methods, means, organizational procedures and evaluation), to make adaptations, adjustments and corrections in (study plan, descriptive letters or programs; as well as in didactic planning).

The observation guide: This instrument was implemented with the aim of checking the pedagogical intervention of teachers during the teaching-learning process. It facilitated the collection of data, provided us with valuable information for analysis and interpretation and reflection; in addition, to observe how teachers perform by applying science and innovation to improve didactics in pedagogical practice.

The evaluation scale was used, which is described without continuation.

They always comply (5): It corresponds to teachers who meet the parameters of the activities presented in the observation guide, and one corresponds to the object of study, science and innovation to improve didactics in pedagogical intervention.

Sometimes they comply (3): When teachers begin to present their ideas about science and innovation, but they do not conclude satisfactorily to present their ideas exponentially to improve didactics in pedagogical intervention.

They do not comply (1): It is up to teachers on very short occasion to use some of the indicators that seem to be reflected in the observation guide.

Questionnaire: The questionnaire was applied to students with the aim of checking whether teachers who teach the classes and effectively comply with science and innovation to improve didactics during the teaching-learning process, contains six items with dichotomous questions 
w orhether or not. The results were determined, by means of the percentage calculation. Key Informants: Making the decision by the research team that all people with the academic degree of Doctors of Science in Education, with more than 15 years of experience, were selected as key specialists or informants on the subject, we modified the instruments applied at the diagnostic stage, these adjustments were made consistently to check the variables and indicators of the instruments, according to the research hypothesis.

Inclusion Criterion: We had the managers and teachers of the Department of Sports Sciences and the Academy of Psychopedagogía who provided us with their consents.

Statistical analysis: It was used with the aim of specifying reliability and validity data with the SPSS version 23 statistical program, according to the mean statistics, deviation standard, coefficient of variation, confidence level to know the dispersion of the mean values and with a confidence level of (90\%), made to the 31 students and the eight teachers investigated.

\section{Procedures}

It is important that managers, teachers and students identify with prior notice to make an affective and cordial climate in a previous meeting. The times were made every three months, for two years with the group students and teachers research reasons; in addition, the instruments were applied under the same natural conditions so as not to affect such a research process. It is essential to highlight the protection of the code of ethics and consent.

The research tools were implemented at three times during the 2017-201 school year.

In a first stage of piloting it was used to adjust and decrease errors in terms of instrument applicability; in addition, an approach was made to check the level of acceptance by the subjects investigated. At the diagnostic stage, the validity and reliability of key informants was confirmed; in addition to knowing and collecting significant levels of data. In the final stage, we applied the research instruments and corroborated the results obtained with the diagnostic phase, then checked that the results yielded are similar, with a minimum of error and a confidence interval of $(90 \%)$.

\section{Results}

Below are the most relevant findings, according to the techniques applied for observation and questionnaire.

In Figure 1, the percentage results of the 31 student participant subjects investigated can be seen, by their respective genders. In relation to the female gender they correspond to $(51.62 \%)$; while $(48.38 \%)$ is related to the male gender. 
Figure 1 Participating subjects of students by gender.

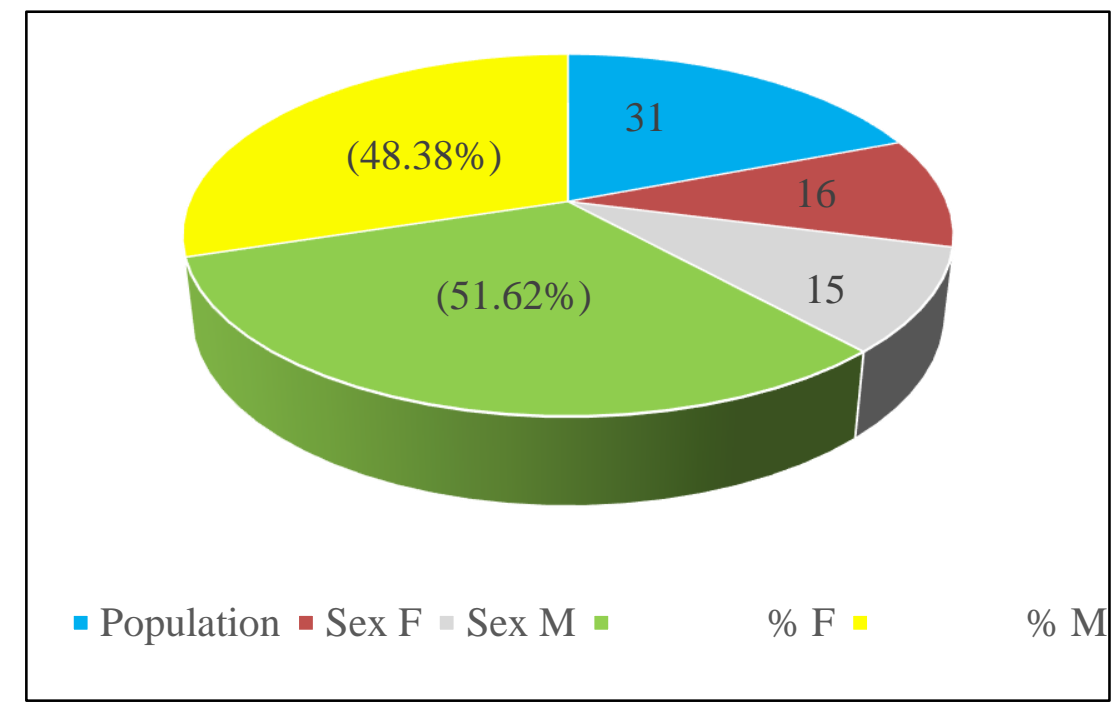

Related to Figure 2, the results of the teacher's gender can be specified, where (62.5\%) belong to the female gender. $(37.5 \%)$, is associated with male gender.

Figure 2 Teaching participants by gender.

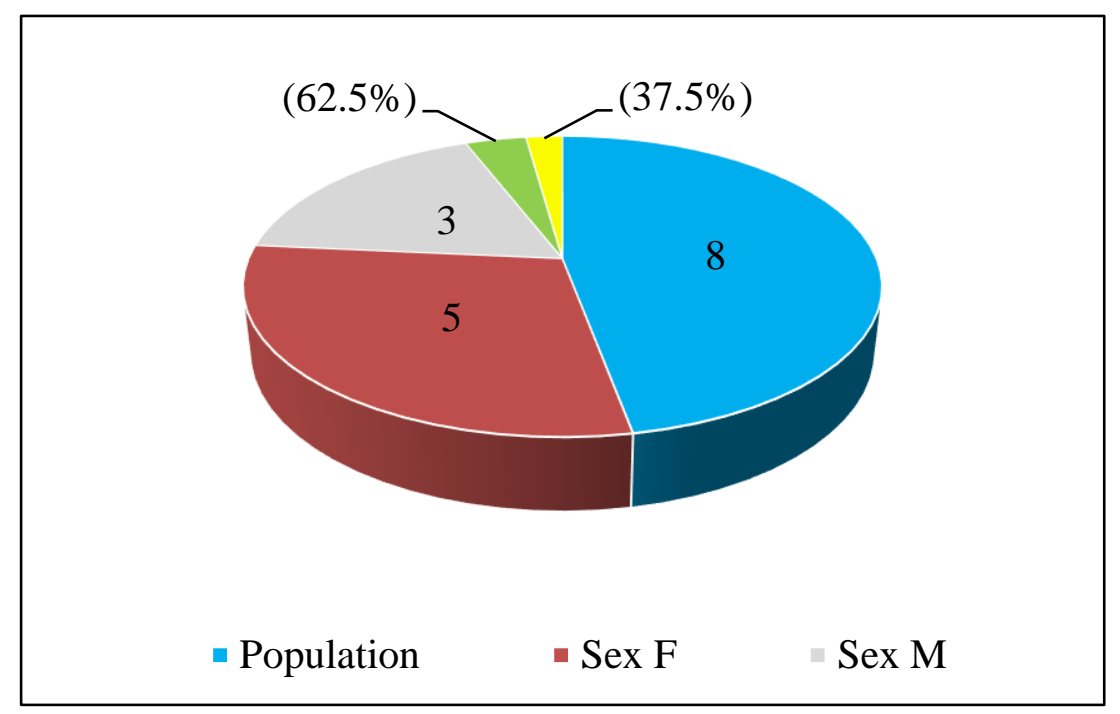

The most significant results obtained in the observations made seven of the teachers are presented, always meet guidance and emphasize the objectives of the class in their pedagogical interventions. The objectives are projected as a guiding and directing category; in addition as a future action of aspiration of orientation, according to the socially programmed objectives, that the student consciously endorses. 
With regard to whether teachers use the methods of science in the course of classes in their pedagogical interventions, five of these always comply, with these activities so essential for science by virtue of the complex and dynamic changes they have produced. In this regard, Oviedo (2012), "thisset of new challenges sets up a new scenario conducive to innovation and the developmentof newinitiatives by teachers". (p.14).

As for whether teachers are innovative throughout the teaching-learning process in their classes, five teachers always comply. Pedagogical intervention to improve didactics has to be an innovative organization, dedicated to the correct use of innovative methods as an assertive, leading, creative personal attribute, with concrete actions and objectives, as a necessity to meet the needs given in the teaching-learningprocess (Sánchez et al., 2018).

On the other hand, if teachers apply the pedagogical principles of didactics during their interventions in their classes, five always comply, according to ethical principles, responsibility, perseverance, which contribute to the strengthening of the emotional staff, spiritual and bodily growth of students of the Bachelor's Degree in Physical Culture, the University of Sonora (UNISON).

As to whether teachers use the structural categories of didactics during their pedagogical interventions, six teachers always comply with the objective components, content, methods, forms, teaching media teaching strategies, evaluation. They lead to better performance of pedagogical intervention.

\section{Table 3}

Observation results during pedagogical intervention to improve didactics.

\begin{tabular}{|c|c|c|c|c|}
\hline No & Activities to be observed & $\begin{array}{c}\text { They } \\
\text { always } \\
\text { comply } \\
\text { (5) }\end{array}$ & $\begin{array}{l}\text { Sometimes } \\
\text { they meet } \\
\text { (3) }\end{array}$ & $\begin{array}{l}\text { Not } \\
\text { compliant } \\
\text { (1) }\end{array}$ \\
\hline 1 & $\begin{array}{l}\text { Teachers guide and emphasize the } \\
\text { objectives of the class in their } \\
\text { pedagogical interventions. }\end{array}$ & 7 & 1 & 0 \\
\hline 2 & $\begin{array}{l}\text { Teachers relate content to science } \\
\text { during classes in their pedagogical } \\
\text { interventions. }\end{array}$ & 4 & 3 & 1 \\
\hline 3 & Teachers use the methods of science in & 5 & 2 & 1 \\
\hline
\end{tabular}


the course of classes in their pedagogical interventions.

Teachers link theory with practice,

4 according to the pillars of education in

their pedagogical interventions.

Teachers are promoters of analysis,

synthesis, reflection and interpretation to improve didactics in pedagogical

work.

Teachers develop cultural, artistic, constructivist and humanistic thinking by using the scientific method in their

pedagogical interventions.

Teachers are innovative throughout the teaching-learning process in their

7 pedagogical interventions during their classes this section is linked to the vision of the University of Sonora.

Teachers apply the pedagogical principles of didactics during their

8 interventions in their classes according to the mission of the Sonoran University.

Teachers use the structural categories

9 of didactics during their pedagogical interventions.

Teachers promote scientific and

10 innovative culture in students through their pedagogical interventions.

According to the results of the stenographers applied to the observations of the eight teachers, the population mean is 4.7 with the required normality, for a standard deviation from the mean value 1.16; that is, according to the classes observed in general teachers always comply with the structural categories of didactics such as: objectives, content, methods, forms, didactic 
strategies teaching means, evaluation. In addition, the confidence level is (90\%), with a coefficient of variation is 0.25 . Check table 3 .

Figure 3 Statistical results of observations at the stage in the final stage.

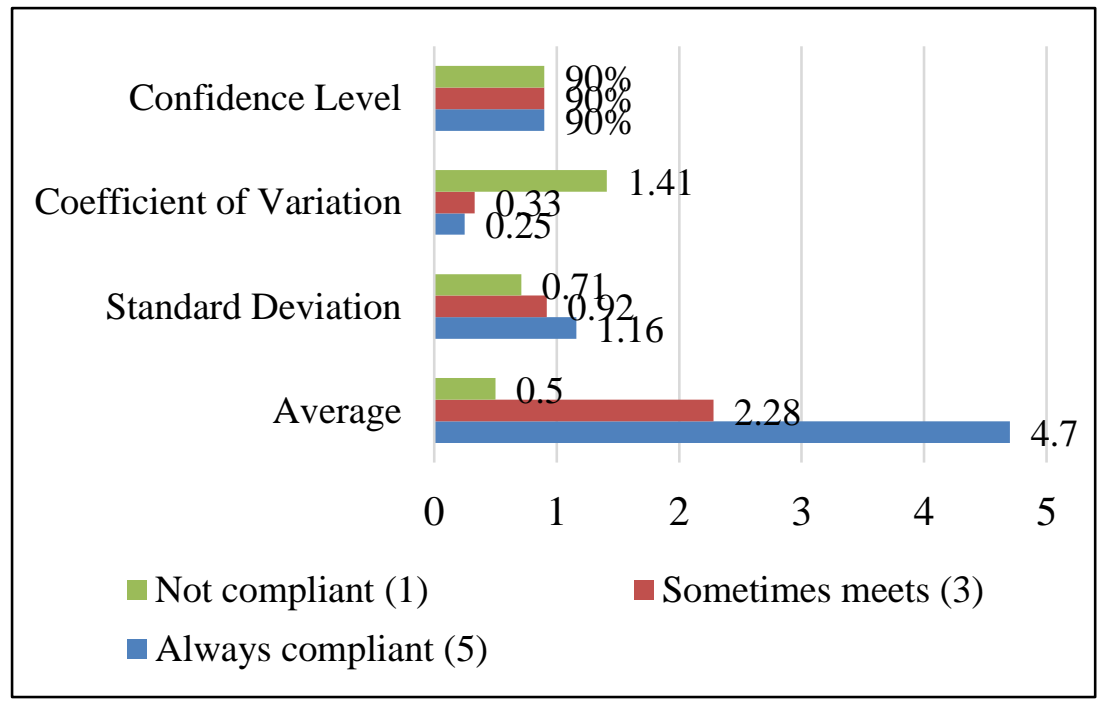

Based on the most significant results found related to the questionnaire applied to students of the Bachelor of Physical Culture, we find that $(0.58 \%)$, of the students investigated consider that teachers do not always apply science in the contents of their class subjects.

The answers offered by students in question number two in order to, if teachers tend to promote analysis, synthesis, reflection and interpretation to improve subjects during classes so $(0.52 \%)$, they indicate that during their classes the analysis, synthesis, reflection and interpretation are achieved to improve subjects during classes.

In question three of the questionnaire, we find that teachers are innovative during the application of their classes during their intervention of the teaching-learning process with $(0.52 \%)$.

With regard to question four asked to those investigated, we found the following results on $(0.52 \%)$, they expressed that teachers do not contribute to boosting scientific and innovative culture through their pedagogical interventions, considering themselves an interesting fact, because science allows us to make decisions to accept or reject scientific theories based on the results that are significant.

As the results of question five of the questionnaire, we were provided with the following data on $(0.55 \%)$, they replied that teachers do not promote scientific culture, for this reason, this perception that students have, would allow us to make decisions in accepted ways to advance the cultural and historical thinking that corresponds to them to live in this 21 st century. 
Finally, students provide us with their criteria, if teachers apply the objectives, methods, teaching strategies, means of teaching and evaluation in an accepted manner $(0.52 \%)$ expressed that teachers if they comply with the structural components of the teaching-learning process.

Figure 4 Statistical results of the questionnaire at the stage in the final stage.

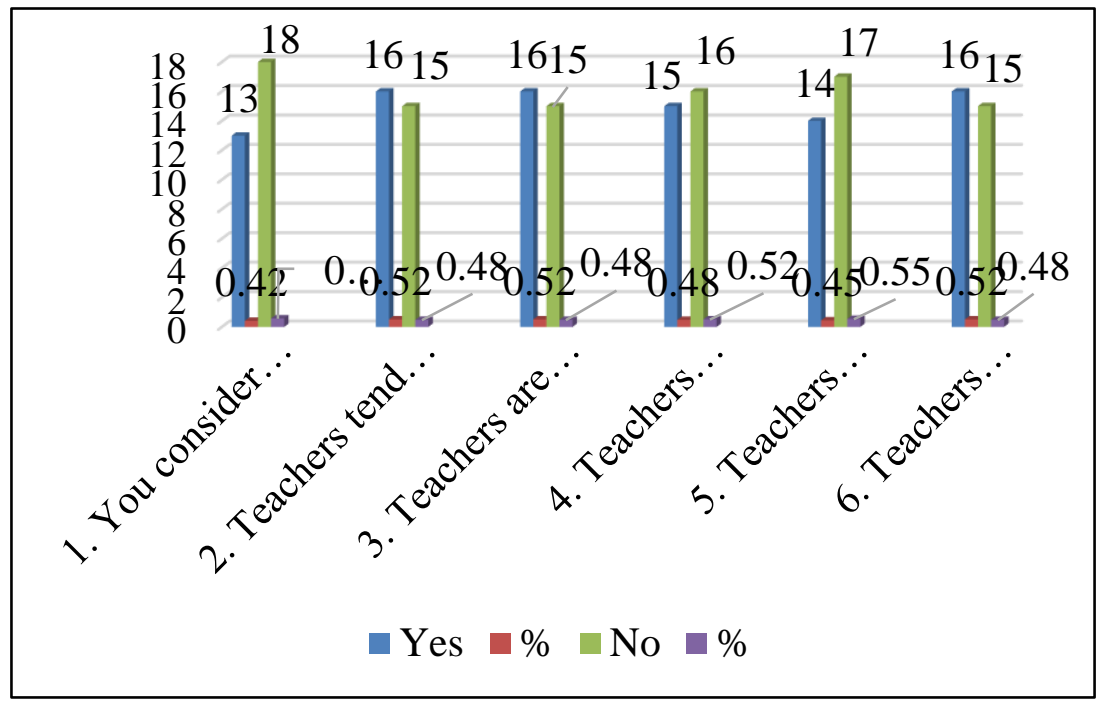

\section{Discussion}

Many of the teachers investigated during their pedagogical intervention do not apply science, seen in this way this work do not seek to guide the importance of science and innovation as change to improve attitude in the agents involved in the teaching-learning process, allowing the emergence of new ideas, answers and perspectives, such as the needs and difficulties that we will seek in the university complex context where we are located. (González and González, 2017 b).

It is inescapable pedagogical intervention in scientific disciplines, in particular didactics, to contribute to the contribution not only of knowledge in the field of education, they must promote teaching and learning as an essential means of transmitting science and innovation.

In this regard, pedagogical intervention is the intentional action it develops in the educational task in order to meet the structural categories of didactics as objectives, content, methods, forms, teaching strategies means of teaching, evaluation to justify the fundamentals of knowledge, according to the functioning pedagogical intervention to improve didactics through science and innovation (Touriñán, 2011).

Such broad issues tend to size the role of statements that have to do with the effective, efficient and effective teaching "duty" inside the classroom in search of the desired educational quality; 
in this sense, it may happen that teachers lack the resources of science as a paradigm of knowledge and innovator and leave behind traditional and reproductive teaching, where science and innovation for pedagogical intervention, contribute to developing a dynamic process and providing the quality of teaching.

It is important to analyze the relationship between science and innovation, such as the role attributed to didactic activities within the innovative process to improve didactics in pedagogical intervention, for much innovative is to invent something new for us to improve, propose, solutions that lead to design a relationship with the theoretical and empirical methods of educational science, propose new teaching resources implying individually and grouply to students to manifest their perspectives of analysis , reflection, may or may not be innovation, (Barraza, 2005, p.21).

For this reason, teachers and educational authorities work for the well-being of development and comprehensive training of students, with the aim of improving didactics in pedagogical interventions, to carry out a reform from didactic planning based on science and innovation to redirect educational quality.

In other words, the Mission of the University of Sonora is to train comprehensive and competent professionals with a high quality and relevance, nationally and internationally, linked to teaching with generation; as well as the application and transfer of knowledge andtechnology. (UNISON, p. 53).

\section{Conclusions}

In conclusion, we can say that pedagogical interventions are alternatives to improving didactics through science and innovation, being a way for teachers to propose new ways of fostering a change in a culture of knowledge in students; in addition to having a scientific teachinglearning process, according to the structural categories of didactics.

Pedagogical interventions provide solutions for teaching work as a significant means in the integral training of students, based on the theoretical and empirical methods of science to improve the teaching-learning process.

\section{References}

Abreu, O., Gallegos, M. C., Jácome, J. G., \& Martínez, R. J. (2017). Didactics: Epistemology and Definition at the Faculty of Administrative and Economic Sciences of the Technical University of Northern Ecuador. University education,10(3),81-92. https://dx.doi.org/10.4067/S0718-50062017000300009 
https://scielo.conicyt.cl/scielo.php?script=sci_arttext\&pid=S0718-50062017000300009

Albert, M. J. (2007). Educational research. Totic keys. Editorial. Mc Graw Hill.

Arias, M., and Navarro, M. (2017). Epistemology, Science and Scientific Education: premises, questions and reflections to think about scientificculture. Journal, Research News in Education, 17(3), 1-20.

doi: $10.15517 / a i e . v 17 i 3.29878$

https://www.scielo.sa.cr/pdf/aie/v17n3/1409-4703-aie-17-03-00774.pdf

Arteaga, E., Arteaga, L.A., \& Del Sol, J. L. (2016). Teaching science in the new millennium.

Challenges and suggestions. University and Society Journal, 8(1), 169-176.

http://scielo.sld.cu/scielo.php?script=sci_arttext\&pid=S221836202016000100025\&lng\&tlng

Barraza, A. (2005). A conceptual understanding of educational innovation. Journal of Educational Innovation, 5(28),19-31.

https://www.redalyc.org/articulo.oa?id=1794/179421470003

Benitez, L. (2016). Evaluation and pedagogical intervention in teacher training. A thoughtful action in the classroom. IE Journal of Educational Research of REDIECH, 7(12), 42-51. https://doi.org/10.33010/ie_rie_rediech.v7i12.81 https://www.rediech.org/ojs/2017/index.php/ie_rie_rediech/article/view/81/75

Briscoe, C. (1991). The dynamic interactions among beliefs, role metaphors, and teaching practices: A case study of teacher change. ScienceEducation, 75(2), 185-199. https://doi.org/10.1002/sce.3730750204

Bunge, M. (2017). The scientific approach. Cuban Journal Public Health, 43(3), 1-29. http://www.revsaludpublica.sld.cu/index.php/spu/article/view/1001

Carbonell, S. J. (2001). The adventure of innovating. Change at school. Journal of Pedagogy, 24(71), 469-473.

http://ve.scielo.org/scielo.php?script=sci_arttext\&pid=S079897922003000300006\&lng=es\&tlng=es

From Longhi, A. L., Ferreyra, A, Paz, A., Bermudez, A., Solís, M., Vaudagna, E., Cortez, M., Lozano, L., \& Parietti, M. (2004). Innovative teaching strategies for the teaching of natural sciences in school. UNIVERSITAS. Publishing. University Scientist of Cordoba. 1-20. http://www.inv.communicare.efn.uncor.edu/wpcontent/uploads/2013/05/Estrategias_didacticas_innovadoras_para_la_ensenanza_de_las ciencias_naturales_en_la_escuela_media.pdf

Diaz, A. (1998). Research in the field of didactics. Historical models. Educational Profiles. 
Scientific Journals of Latin America, (80),1-21.

https://www.redalyc.org/articulo.oa?id=132/13208002

Ezpeleta, J. (2004). Educational innovations. Reflections on contexts in their implementation. Mexican Journal of Educational Research, 9(21),403-424.

https://www.redalyc.org/articulo.oa?id=140/14002106

Fernández, I., Vega, J., \& Gutierrez, A. (2011). Science and Innovation. A complex and evolutionary relationship. Arbor Journal Science, Thought and Culture, 187(752), 10771089. doi.org/10.3989/arbor.2011.752n6005

http://arbor.revistas.csic.es/index.php/arbor/article/view/1390

Fourez, G. (2008). How knowledge is developed. Epistemology from a constructivist socioapproach. Editorial. Narcea.

Fuertes, C. (2014). Teaching proposals for the teaching of Social Sciences in Higher Education. Journal of the Faculty of Education of Albacete, 29(2), 141-157. http://www.revista.uclm.es/index.php/ensayos

Garcia, L. (2008). Epistemological approach to the concept of science: a basic proposal from Kuhn, Popper, Lakatos \& Feyerabend. Scaffolding Magazine, 4(8), 185-202. http://www.scielo.org.mx/scielo.php?script=sci_arttext\&pid=S187000632008000100008\&lng\&tlng

González, J. J., and González, A. (2017 a, b). Educational innovation and its scientific dissemination. Thematic Collection. Publishing. Catholic University of Murcia, 1-166. http://hdl.handle.net/10952/3293

Guerra, K., Perez, R., \& Fornet, E. (2014). Proposal of a technology for the management of innovation projects in the territorial system of science and innovation in Cuba. Cuban Journal of Information in Health Sciences, 25(4), 367-381.

https://www.redalyc.org/articulo.oa?id=3776/377645759002

Macanchí, M. L., Orozco, B.M., \& Campoverde, M. A. (2020). Educational, pedagogical and didactic innovation. Conception for practice in higher education. University and Society Journal, 12(1), 396-403.

http://scielo.sld.cu/scielo.php?script=sci_arttext\&pid=S221836202020000100396\&lng=es\&tlng=es

Margalef, L., and Arenas, A. (2006). What do we mean by educational innovation? a purpose of curriculum development. Journal Educational Perspective, Teacher Training, (47),13-31. https://www.redalyc.org/articulo.oa?id=3333/333328828002

Mellado, V. (1996). Conception and classroom practices of science teachers, in initial primary 
and secondary training. Journal of Research and Didactic Experiences, 14(3), 289-302. https://www.raco.cat/index.php/Ensenanza/article/view/21460

Mexico. Secretary of Public Education (2009). Primary Basic Education Curriculum. Curriculum. Test stage. 264.

https://www.sep.gob.mx/work/models/sep1/Resource/3f848841-8476-4596-9835d71e306221a3/a494.pdf

Mexico. University of Sonora. (2017). Institutional Development Plan 2017-2021. Commitment to the academic quality, institutionalization and sustainable development of society. Editorial. University of Sonora. https://www.unison.mx/institucional/pdi2017-2021.pdf

Monserrat, J. (1987). Evolutionary epistemology and science theory. Editorial. University of Comillas.

Ortiz, E.A. (2015). Assessing the scientific impact on educational research through a case study. Electronic Journal of Educational Research, 17(2), 89-100. http://redie.uabc.mx/vol17no2/contenido-ortizt.html

Oviedo, P. E. (2012). Innovate teaching. Strategies derived from research. http://biblioteca.clacso.edu.ar/Colombia/fce-unisalle/20170117031111/Innovarens.pdf

Pérez, A., and Zagalaz, M. L. (2001). Creativity course for Physical Education teachers. EFDeportes Magazine, (31), 1-1. https://www.efdeportes.com/efd31/creativ.htm

Pierre, J., \& Pallán, C. (1979). Research in Education: Its importance to politics. Journal of Higher Education (32), 1-17. http://publicaciones.anuies.mx/pdfs/revista/Revista32_S1A1ES.pdf

Sánchez, J.M. (2005). Institutional educational innovation and its impact on the teaching centers of Castilla-La Mancha. REICE. Ibero-American Journal on Quality, Effectiveness and Change in Education, 3(1), 638-664. https://www.redalyc.org/articulo.oa?id=551/55130163

Sánchez, M., Escamilla, J., and Sánchez, M. (2018). What is innovation in higher education? academic reflections on educational innovation. (Presentation). Perspectives of Educational Innovation at Universities of Mexico: Experiences and Reflections of RIE 360. Mexico City. Mexico.

https://cuaieed.unam.mx/descargas/investigacion/Perspectivas-de-la-innovacioneducational-in-universities-of-Mexico.pdf

Tierney, W. G., \& Lanford, M. (2016). Conceptualization of innovation in higher education. In 
M.B. Paulsen (Ed.), Higher Education: Manual of Theory and Research, 1-40. http://doi.org/10.1007/978-3-319-26829-3_1

Touriñán, J.M. (2011). Educational Intervention, Pedagogical Intervention and Education: The Pedagogical Gaze. Portuguese Journal of Pedagogy,283-307. https://doi.org/10.14195/1647-8614_Extra-2011_23 https://impactum-journals.uc.pt/rppedagogia/article/view/1647-8614_Extra$\underline{2011 \_23 / 771}$

Zimmy, G. H. (1961). Method in experimental psychology. Publishing. Ronal Press. 